\title{
GERENCIA Y RESPONSABILIDAD SOCIAL: CONSTRUCCIÓN COLECTIVA DESDE LA COMPLEJIDAD Y LA ACCIÓN COMUNICATIVA
}

\author{
Roemith Sánchez López* \\ https://orcid.org/0000-0002-2890-0428 \\ Isaida Cabrera Rojas** \\ https://orcid. org/0000-0003-2032-4304
}

RECIBIDO: Junio 2020 / ACEPTADO: Noviembre 2020 / PUBLICADO: Enero 2021

Como citar: Sánchez López, Roemith; Cabrera Rojas, Isaida. (2021). Gerencia y responsabilidad social: construcción colectiva desde la complejidad y la acción comunicativa. Telos: revista de Estudios Interdisciplinarios en Ciencias Sociales, 23 (1), Venezuela. (Pp. 100-114).

DOI: www.doi.org/10.36390/telos231.08

\section{RESUMEN}

El propósito de la investigación es interpretar las relaciones dialógicas que confrontan y complementan la Gerencia y la Responsabilidad Social, como proyecto de construcción colectiva. El enfoque cualitativo tomando como postura epistemológica de: la Teoría de la Complejidad de Morín (2005), sustentado en el principio dialógico, el recursivo y el hologramático que permite la unión del conocimiento de las partes con el conocimiento del todo; la Teoría de la Acción Comunicativa de Habermas (1987). Apoyada como opción metodológica en fundamentos fenomenológicos de Husserl (1962), fundamento ontológico de Heidegger (2003) y enfoque hermenéutico desde Gadamer (1993); esta triada de enfoques son la base para desplegar las plataformas filosóficas de la investigación. La investigación está organizada en cuatro etapas: la observación participante, el diálogo entre actores, interpretación y teorización. Se aplicó la entrevista en profundidad a los voceros (actores sociales), basada en guías y el análisis de documentos legales; para sistematizar los datos en categorías a través del software ATLAS.ti. Los hallazgos permitieron construir la aproximación teórica, que evoca una gerencia emancipadora, definida como una unidad entramada de saberes y competencias de los líderes sociales, que se fundamenta en la responsabilidad con ellos mismos y su entorno, para el establecimiento de nuevas estructuras sociales voluntarias que compartan la visión holística, innovadora y humanizada.

Palabras clave: Gerencia; Gerencia Emancipadora; Responsabilidad Social; Comunas; Construcción colectiva.

\footnotetext{
* Profesional Aduanero y Tributario, Servicio Nacional Integrado de Administración Aduanera y Tributaria. Doctora en Ciencias Gerenciales, Especialista en Gerencia Pública, Licenciada en Contaduria Pública. Correo electrónico: roemithsan@gmail.com

** Profesora Asociado de la Universidad de Oriente, Núcleo Nueva Esparta. Doctora en Ciencias Gerenciales, Especialista en Ciencias Administrativas mención Gerencia General, Licenciada en Estadística. Correo electrónico: isaidacabrera@gmail.com
} 


\section{Management and social responsibility: collective construction from the complexity and communicative action}

\section{ABSTRACT}

The purpose of the research is to interpret the dialogic relationships that confront and complement Management and Social Responsibility, as a project of collective construction. The qualitative approach, taking as an epistemological position: Morín's Complexity Theory (2005), based on the dialogic, recursive and hologrammatic principles that allow the union of the knowledge of the parts with the knowledge of the whole; Habermas' Theory of Communicative Action (1987). Supported as a methodological option in phenomenological foundations of Husserl (1962), ontological foundation of Heidegger (2003) and hermeneutical approach since Gadamer (1993); This triad of approaches is the basis for deploying the philosophical platforms of research. The research is organized in four stages: participant observation, dialogue between actors, interpretation and theorizing. An in-depth interview was applied to the spokespersons (social actors), based on guides and the analysis of legal documents; to systematize the data into categories through the ATLAS.ti software. The findings allowed the construction of the theoretical approach, which evokes an emancipatory management, defined as a woven unit of knowledge and skills of social leaders, which is based on responsibility with themselves and their environment, for the establishment of new voluntary social structures that share the holistic, innovative and humanized vision.

Keywords: Management; Emancipatory Management; Social Responsibility; Communes; Collective Construction.

\section{Introducción}

Las organizaciones en el contexto mundial han sufrido cambios muy significativos durante los últimos años. En la República Bolivariana de Venezuela, la aprobación y publicación en el año 2000, de una nueva Carta Magna estableció un "Estado democrático y social de Derecho y de Justicia" (Asamblea Nacional de la República Bolivariana de Venezuela, 2000, Constitución de la República Bolivariana de Venezuela, Artículo 2), que se considera la base para dar un giro a la concepción socio política que promueve una forma de gobierno distinto a través de la agrupación de las comunidades en Comunas, dando origen a un acoplamiento entre los miembros de estos espacios socio-geográficos, organizado por una estructura de sociedad cambiante, heterogénea y compleja.

En el entorno comunal las personas que actúan socialmente son designadas como Voceros, constituyéndose núcleo fundante para ejercer la participación protagónica y fortalecer el poder popular; estos líderes sociales se encuentran sumidos en pensamientos propios y colectivos, por convenios y discrepancias, lo reflexivo y lo instintivo, que impulsa a un análisis conductual sobre ellos. De allí, que apremie tener una visión de la realidad que lo circunda, originando los nuevos modelos de sociedad, desde la génesis de lo transdisciplinario, donde la Gerencia y la Responsabilidad Social en la concepción emergente tienen un lado luminoso que las hace portadora de un proyecto histórico y que responden al clamor de los colectivos populares, para asumirse como potenciadoras de la emancipación. Drucker en la introducción del libro de Hesselbein et al., (2006), hace referencia a su basta experiencias tanto con 
Gerencia y responsabilidad social: construcción colectiva desde la complejidad y la acción comunicativa

ejecutivos denominados gigantes de la industria como directivos de pequeñas organizaciones; también, distingue a los gerentes que ejercen el liderazgo y los que no; $y$ a manera de síntesis señala que: "El liderazgo no es rasgo, privilegios, títulos o dinero: es responsabilidad" (p. 13); una visión gerencial que fortalece la postura sostenida en esta investigación, que respalda la emancipación del líder para asumirse como gerente.

La existencia de las Comunas constituidas en diversas regiones venezolanas, exigen la realización de estudios orientados a la caracterización propia de la Gerencia y de la Responsabilidad Social, por la diversidad de personas que la integran, es decir, grupos sociales comunitarios heterogéneos, que en el ámbito geográfico trabajan en función a proyectos sociales. En consecuencia, resulta interesante revisar los referentes teóricos epistémicos de estos constructos que definen el comportamiento de voceros y líderes comunales de acuerdo con teorías existentes con la intención de fundamentar epistemológicamente las mismas, en la búsqueda de proponer nuevos enfoques gerenciales como factor coadyuvante en el proyecto de construcción colectiva.

Es importante dejar claro que dentro de esta perspectiva los ciudadanos, buscan aquellas acciones y estrategias que les permitan encontrarse como grupo, mejorar la percepción sobre sí mismo y la satisfacción de las necesidades conjuntas. Lo que origina actividades de integración, con la firme convicción de no producir traumas y lograr el equilibrio social. Al respecto Barreto (2011), indica que: "(...) la Comuna es una nueva forma de pensamiento y un nuevo paradigma epistemológico que restituye y refunda una nueva dimensión del sujeto" (p.41). Por ende, las Comunas exigen una nueva misión de las personas, asociada a una lucha permanente y a una nueva forma de pensar.

Al momento de tratar de interpretar el significado de algunos elementos teóricosepistemológicos que posibilitan la relación dialógica de la Gerencia y la Responsabilidad Social, como proyecto de construcción colectiva, conviene, la deconstrucción y la refundación de la noción de estos constructos desde la complejidad y la acción comunicativa, procurando precisar un nuevo enfoque gerencial. En este caso, una crítica a la teoría y la epistemología significa debatir criterios de validez, coherencia y pertinencia atendiendo a aspectos que incluyen y excluyen la participación en los procesos toma de decisiones asertiva para mejorar la gestión de espacios comunales, según los aportes de cada uno de los ciudadanos que la integran.

Interesa entonces, precisar algunos supuestos de partida, que pueden servir de ejes orientadores en la tarea de repensar las categorías fundamentales para la crítica ideológica y la elaboración conceptual. Al momento de hacer esta investigación, se considera conveniente iniciar desde la Teoría de la Acción Comunicativa de Habermas (1987), porque la misma se aplica en las ciencias humanas donde está incluida la hermenéutica, es decir, encaminado a la comprensión y al entendimiento entre personas. Seguidamente se aborda a través del pensamiento complejo de Morín, usado como base para orientar la interacción comunicacional entre los actores sociales, para modelar o cambiar el conocimiento existente y pasar hacia lo nuevo, como sostiene Morín (2003): "(...) aprendimos que todo lo que es, sólo pudo nacer en el caos y la turbulencia, (...) el cosmos se organizó al desintegrarse (...)" (p. 32).

Hablar de pensamiento complejo implica en la forma de pensar y la forma de actuar del ser humano, inmerso en la interacción entre los actores sociales activando la gerencia con enfoque transdisciplinario para lograr la integración y la multimensionalidad que desafía el conocimiento. Una gerencia con visión de pensamiento complejo impulsa a crear un sistema no 
fragmentado, dividido o reducido, es un proceso para develar lo que a simple vista no se observa, es un tejido de eventos, acciones, relaciones, reacciones, de la ambigüedad, de la incertidumbre, del desorden y del orden que caracteriza a la conjunción. Sin el orden, no habría ningún elemento de estabilidad con el cual fundar una organización y sin el desorden, no existiría los nuevos comienzos, la diversidad, como lo sostiene Morín (2005), "(...) no habría innovación, creación, evolución. No habría existencia viviente ni humana" (p. 126).

Los hombres y mujeres que actúan en estos roles de actores sociales viven y construyen sus realidades influenciados por sus creencias, el lenguaje, la observación, la subjetividad y la propia acción sobre lo real. Convirtiendo la relación entre ellos en el pilar para construir un ambiente diferente, inclusivo, democrático, protagónico y participativo (según los preceptos constitucionales de Venezuela) y en ocasiones representativo, calificada en conjunto como un mecanismo de interrelaciones complejas. Por eso, el interés de investigar los aspectos axiológicos compartidos por los miembros de la comunidad y en su preocupación por el futuro del país, como líderes comunales. Constituyendo una propuesta dentro de los proyectos de gestión, fomentados en el desarrollo de competencias individuales producto de la dinámica colaborativa dirigida a la solución de problemas socio comunales en ambientes de democracia, justicia y solidaridad.

El aporte a las ciencias gerenciales, se refleja en la interpretación del comportamiento de los líderes y voceros, revisar las bases epistémicas de la Gerencia y la Responsabilidad Social en una concepción incipiente, que permita entender la presencia de numerosos cambios en todos los órdenes de la vida humana; transformaciones basada en la plena comprensión por parte del ciudadano común y corriente, así como por parte de aquellos que desarrollan su actividad profesional dentro y fuera de las instituciones del Estado, por ser una práctica asertiva para comprender el convivir en sociedad y los intereses que la distinguen a escala mundial, nacional y regional.

Si se parte del conocimiento precedente en el entorno comunal, surge el interés de dar respuesta a inquietudes para desarrollar la investigación, con el propósito de fundamentar epistemológicamente la Gerencia y la Responsabilidad Social, que conduzca a nuevos enfoques gerenciales como factor coadyuvante en el proyecto de construcción colectiva promovido por la participación protagónica de los voceros comunales. Fundamentada en la fenomenología y la hermenéutica, a partir de esta perspectiva se plantean un anclaje teórico sobre: Fundamentos fenomenológico desde Husserl (1962), de dar la palabra a las cosas mismas, de Heidegger (2003), para quien el lenguaje es la casa del ser, donde cobra peso la teoría encerrada entre la filosofía y ciencia con objetivos vistos desde lo externo, además de Gadamer (1993), quien señala que el diálogo es el hilo conductor. Estos reconocidos autores muestran las evidencias fenomenológicas, que permite comprender las palabras de los voceros, donde los testimonios expresados por los voceros sobre su realidad en el entorno sociocomunal y recogidos en esta investigación, representan la base para interpretar.

Se emprende metodológicamente con un diseño de campo, por considerar a los voceros y líderes comunales la parte central de esta investigación, para caracterizar su comportamiento de acuerdo con las teorías existentes. Sustentada en la descripción (arqueología) y explicación (genealogía), como momentos esenciales en el desarrollo de la investigación que nos llevó a considerar: La observación participante, el diálogo y la Interpretación. Los datos fueron recolectados a través de las entrevistas: aunque en el estudio de la población generalmente es 
sustentada en un número significativo de integrantes de la misma, en este caso asumimos que: "(...) Es a la vez lógico y más eficiente seleccionar un número de diversidad intencionalmente, a fin de cubrir todas las variantes relevantes (...) del fenómeno (saturación)" (Jansen, 2013, p. 51).

Al respecto, Mendieta (2015), señala que "del número de sujetos no es lo central en investigación cualitativa" (p. 1149). Por su lado, Marshall (2016), indica que: los investigadores cualitativos identifican que algunos informantes son "más ricos" que otros (p. 523); y pueden aportar datos para facilitar la comprensión del investigador. Por la diversidad de autores y posturas no es objeto llegar al punto de controversias, razón por la cual esta investigación se apoya en la selección intencionada, eligiendo para la aplicación de la entrevista a cinco informantes claves que forman parte de las Comunas ubicadas en el Municipio Tubores del estado Nueva Esparta.

Para analizar los datos generados se aprovecha de las ventajas que ofrece el programa ATLAS.ti, diseñado por Mühr y Friese (2004), como herramienta computacional para analizar datos cualitativos de los grupos de testimonios textuales. Esta investigación arrojó: 23 categorías, 8 sub categorías, 9 redes y 3 grupos de redes. Sobrepasando la descripción para obtener el nivel conceptual que contribuye a la teorización investigativa, que surge entre el método y la técnica interpretativa sobre la incidencia de la responsabilidad social en la visión de la gerencia.

\section{Repensando la Gerencia y Responsabilidad Social, rompiendo paradigmas}

En la investigación partiendo de los datos contribuidos por los actores sociales, condicionados por el contexto comunal y sus experiencias de vida. Los voceros seleccionados corresponden a las Comunas en el ámbito del Municipio Tubores. Los informantes poseen diversos niveles de instrucción, amplio conocimiento sobre el tema y representan diferentes vocerías, para otorgarle fiabilidad a la investigación; demostrando, estabilidad, seguridad y coherencia en diversos momentos y su proyección en el porvenir. Todo esto con la finalidad de poder crear categorías, códigos y sub-categorías que emerjan como resultado de la evaluación de los datos que surjan desde la investigación; que permitan el análisis y síntesis para construir nuevas propuestas teóricas epistémicas sobre la Gerencia y la Responsabilidad Social, empleando un número reducido de casos para investigar, tal como lo sostiene Carrasco y Calderero (2000). En la tabla siguiente, presentamos en forma resumida todas las categorías y sub-categorías obtenidas a través del programa ATLAS.ti.

Tabla N¹. Categorías y Sub Categorías creadas por el programa ATLAS.Ti.

\begin{tabular}{|l|l|}
\hline $\begin{array}{c}\text { Grupo de documentos } \\
\text { (Sub categorías) }\end{array}$ & $\begin{array}{l}\text { Código } \\
\text { (Categoría) }\end{array}$ \\
\hline Concepto de gerencia & $\begin{array}{l}\text { definición de gerencia } \\
\text { Gerencia vertical }\end{array}$ \\
\hline Lineamientos & $\begin{array}{l}\text { política nacional } \\
\text { ruptura de esquemas }\end{array}$ \\
\hline Nueva gerencia & $\begin{array}{l}\text { complejidad en la gerencia } \\
\text { gerencia con criterio propio } \\
\text { gerencia horizontal } \\
\text { nuevos enfoques gerenciales }\end{array}$ \\
\hline Recursos Responsabilidad Social & $\begin{array}{l}\text { articulación protagonismo y participación } \\
\text { formación del vocero }\end{array}$ \\
\hline
\end{tabular}




\begin{tabular}{|l|l|} 
& valores éticos \\
\hline Responsabilidad Social (Concepto) & $\begin{array}{l}\text { definición de responsabilidad social } \\
\text { responsabilidad personal } \\
\text { responsabilidad social en la estructura }\end{array}$ \\
\hline $\begin{array}{l}\text { Nueva visión de la Responsabilidad } \\
\text { Social }\end{array}$ & $\begin{array}{l}\text { responsabilidad Social compartida } \\
\text { triada vocero, comunidad y entorno político } \\
\text { una nueva responsabilidad Social }\end{array}$ \\
\hline Bienestar & $\begin{array}{l}\text { Comuna } \\
\text { cumplimiento de metas } \\
\text { entramado político } \\
\text { integración vocero comunidad }\end{array}$ \\
\hline Comuna constituida & $\begin{array}{l}\text { actividad del vocero } \\
\text { comuna }\end{array}$ \\
\hline
\end{tabular}

Fuente: Elaboración propia.

En la forma de ser el hombre, biopsicosocial (conexión mente-cuerpo); integrado a las experiencias, su forma de pensar y actuar que permiten visualizar al hombre como un individuo integral, nos permite identificar al vocero y analizar su conducta, sus obras, las labores establecidas, obligación, valores, como se comporta, su accionar ante los otros y su entorno, para obtener aproximaciones sobre si se siente un gerente; en busca de dejar claro un perfil en los nuevos modelos gerenciales y que se construyen un mundo cada vez más interdependiente y globalizado.

Ser responsable va más allá de solo cumplir normas o leyes y de adecuarse a las mismas, implica revisarse primero de manera individual y después colectivamente; así pues, la responsabilidad individual se vincula conla libertad de las personas de demostrar un comportamiento ético. El ejercicio de la libertad no solo es modificar hábitos, costumbres o formas de vida, es gestionar interrelación e intervenir en asuntos colectivos más allá de intereses particulares, según Savater (2004) "(...) la gestión de lo propio en interacción con lo que tenemos en común con nuestros iguales" (p.155). Este autor, lleva a conjugar identidades con vínculos de diferencias, al ejercicio de la libertad como forma de interrelacionar aspectos comunes que permiten la coexistencia; pero siempre con un doble ángulo, la aceptación de una historia colectiva y la emancipación que tiende a desconocer una obediencia a la norma que impone la misma tradición histórica.

En torno a la emancipación, Bauman (2000), expresó: “(...), existe una enorme y creciente brecha entre nuestra condición de individuo de jure y nuestras posibilidades de transformarnos en individuos de facto -o sea, te tomar el control de nuestro destino y hacer las elecciones que verdaderamente deseamos hacer" (p.44). El mencionado autor sostiene ante la posibilidad de cambios, que la persona se puede sentir independiente aun cuando sientan miedo ante tales circunstancias. Ser independiente no es fácil, la emancipación promueve en el hombre que rebusque en su interior para liberarse de todo lo que rodea su existencia.

Los mencionados autores nos dan una posibilidad de repensar la Responsabilidad Social, pero en este caso desde los actores comunales, es ser responsables ante ellos mismos y ante los demás con inclinación al concepto ético. Para visualizar la Responsabilidad Social con un carácter inverso, de lo interno a lo externo, se enfrenta al reto de descontextualizarlo desde la complejidad del mismo y llevarlo al plano comunal, desde el líder que cuenta con la credibilidad ante un grupo social, donde, a mayor responsabilidad mayor credibilidad en su 
Gerencia y responsabilidad social: construcción colectiva desde la complejidad y la acción comunicativa

entorno social. Donde los líderes y voceros pretenden la cooperación de los miembros de la sociedad y la aprobación de sus actos, para consolidar una sociedad que se respalde en sí misma, inclusiva, con espíritu colaborativo.

En algunas ocasiones los líderes y voceros toman decisiones unilateralmente que apunta a la representatividad, en otras corresponde apoyarse en las decisiones colectivas, en ambas hay un gran peso sobre los valores que forma parte de lo interno, que implica vencer el paradigma existente y permear la visión de vulnerabilidad y confianza sobre el líder y las decisiones en consenso. Donde no existen códigos, no hay manuales, no hay nada escrito para orientar la toma de decisiones, sino que la misma se apoya sobre principios éticos. Es importante señalar que, el tema ético en la sociedad actual ha experimentado cambio de mentalidad, por cuanto las personas individualizan su visión ética provocando un caos, que en palabras de Maxwell (1996), se traduce en: "Antes nuestras decisiones se basaban en la ética; ahora la ética se basa en nuestras decisiones. Si está bien para mí, es bueno" (p. 6).

Por lo que Mayol (2007), sostiene que: "la sola enunciación de unos valores no basta" (p. 43), hay que apropiarse de ellos y actuar en concordancia. La responsabilidad a la inversa se aplica de forma intencional como estrategia de los actores sociales, sin estar marcada por patrones ni contradecir a la misma. Trata de lograr beneficios para toda la estructura comunal, a través de la cooperación y trabajo en equipo con sentido de pertenencia que genere confianza, vinculación y participación social, en vez de producir ganancias económicas.

En Venezuela, se están generando nuevos paradigmas del estado, donde se encuentra inmersa la Gerencia, repensada en la construcción de resultado basado en la participación, protagonismo y representatividad, además de tener metas muy concretas que permitirán superar la crisis de un estado paternalista para conducir a la sociedad al logro de sus metas generales a través del crecimiento y logro de aquellos que llevan la voz colectiva.

La construcción de sociedades con valores éticos, facilitará la fundación de nuevos saberes y materializar el cambio que las democracias necesitan; fundamentada básicamente en el principio de la responsabilidad social, que apuntan a criterios sociológicos y antropológicos de los actores sociales, que debe proponer una exaltación de la participación.

Culturalmente, en Venezuela, pensamos que ser el líder forma parte de una realidad social materializada por la necesidad de tener poder, y esto nos lleva a reflexionar en torno a los voceros, por ser elegidos no solo por sus saberes y experiencias en el entorno social y gerencial, sino por aspectos relacionados con su personalidad como: actitud, compromiso, cooperación, perseverancia, comunicación, justicia, sencillez, autocontrol, estar dispuesto a asumir retos, proactividad, gestor del cambio y la transformación, entre otros, que se sustenta según Blanco (2018), en "(...), los principios que definen al ser humano quien es conciencia de sí mismo, racionalidad, socialización (...)” (p. 120). Aunado a ello, retomando a Morín (2005), se puede inferir de la sistematización de los datos aportados por los voceros, que en el sistema comunal existe una estructura invisible de poder que permite el orden y el desorden, consolidado con la ideología, donde la cultura interviene en contra y a favor del mismo.

Los voceros y líderes comunales actúan en calidad de representantes sociales a través de una estructura organizativa abierta, por cuanto viven en constante interacción con un mundo que exige y promueve cambios constantes. Siendo necesario demostrar su capacidad para crear e innovar para hacer frente a situaciones bajo incertidumbre de forma proactiva. Por esta razón, en los pensamientos y acciones de los voceros y líderes comunales debe prevalecer la 
coherencia; en pocas palabras, se requiere de conectividad entre la comprensión y el comportamiento asumido para transformar el mundo con sus sueños e ideales. Zavarce et al.(2009), señalan en torno a la gerencia y al referirse al liderazgo que es uno de los:

"(...) pilares fundamentales que ha de observar la gerencia de hoy para prepararse ante los retos y desafíos que trae con sigo la incorporación de la organización a una sociedad cada vez más abierta e interconectada, que está en plena conformación" (p. 190).

Al hacer un abordaje sobre gerencia, Romero (2006), al referirse al plano latinoamericano, sostiene que la "sociología de la gerencia tendría sentido si se plantea como respuesta de acompañamiento del modelo", vinculada a "la capacitación técnica y la formación en valores de sus dirigentes" para el logro de una "adecuada responsabilidad social" (p. 53). La gerencia naciente requiere de las organizaciones con estructura organizacional flexible y horizontal, donde predomine la comunicación asertivas con innovadoras redes de información que sirva de impulso para el trabajo en equipo, por ser esencial para la concepción y ejecución de los proyectos sociales y las metas en el entorno comunal.

La articulación e interacción de los actores sociales, la comunidad y el estado se reforma a través de la formación académica enfocada a enseñar y aprender a convivir con valores. Consecuentemente, la gerencia en un mundo globalizado integra a los líderes y sus competencias, que necesitan certificar sus conocimientos y las experiencias de llevar a la práctica saberes para producir cambios en su contexto.

A tal efecto, Marcano (2017), sostiene que "Al gerente le corresponde determinadas características que le permitan asumir y cumplir con cabalidad la responsabilidad para gerenciar (...)" (p. 289); además, el autor destaca la importancia del talento para pronosticar situaciones en una sociedad que constantemente experimenta cambios, no se puede dejar de indicar que la personalidad y el comportamiento, a la luz de su entorno cultural siempre tendrán un valor agregado el hecho de ser gerente, y la posibilidad de decontruir y construir nuevos enfoques de manera constante.

La Gerencia necesita de la construcción de relaciones dialógicas y participativas entre voceros, manteniendo la equidad de oportunidades, la estructura organizacional de manera horizontal y funcionamiento basado en la responsabilidad colectiva que le dé respuesta legítima y pertinente a la sociedad actual donde exista la coherencia en el pensar, sentir y actuar de todos sus integrantes y sus contextos. Tratar de conceptualizar a la Gerencia no es una tarea sencilla, por requerir criterios y orientaciones de carácter técnico y lo complejo de la dimensión humana, ambos dependen de experiencias y saberes que contribuyen en gran medida en la construcción a la misma. Todo ello sin dejar de enfocar la condición ciudadana donde se destaca la dimensión intersubjetiva en el espacio colectivo donde se crea y conjuga lo personal y lo grupal, para lograr consolidarse colectivamente.

Aquí no se trata de crear recetas que los voceros y líderes comunales deben asumir con lineamientos hacia determinados comportamientos de acuerdo con la realidad. Por el solo hecho de pretender construir en forma general no se transforma un modelo social de vieja data, debe ir a la educación del hombre, para que éste acepte el compromiso de modificar su entorno y sea socialmente relevante. Ramírez (2012), hace referencia a novedosas formas de interrelacionar gerencia y liderazgo, llegando a expresar que "Un Gerente debe ser un líder" ( $p$. 90), y continúa "liderazgo y gerencia no son conceptos iguales, pero deben ir juntos (...)" (p. 
Gerencia y responsabilidad social: construcción colectiva desde la complejidad y la acción comunicativa

90); una perspectiva gerencial que no contradice la postura sostenida en esta investigación, que respalda la emancipación del líder para asumirse como gerente.

Así, los voceros y líderes comunales lograran ser reconocidos como gerentes cuando demuestren una formación integral que les permita reflexionar y actuar de acuerdo con una gerencia en construcción impulsada por nuevos paradigmas y venciendo esquemas tradicionales de la gerencia; es decir, que tengan la capacidad de empoderarse, a través del diseño, estrategias y acciones encaminadas al logro de metas colectivas en una gerencia social responsable, inmersa en una responsabilidad que nace desde el rol de los líderes y voceros.

No obstante, la gerencia se afianza en todos los conocimientos adquiridos en su transcurso histórico, destacándose lo que Morín (2005), llama un pensamiento complejo, cuando expresa: "No olvides que la realidad es cambiante, no olvides que lo nuevo puede surgir $y$, de todos modos, va a surgir" (p. 118). De lo anterior, se desprende que la ruptura epistemológica que implica el pensar diferente, a través del pensamiento complejo debe ser difundida y aceptada generalmente por el entorno socio-comunal. Por ende, se provocará el verdadero cambio de enfoque, estando a la espera de avances en las perspectivas del campo y definición de la gerencia. En un entramado social cargado de líneas generales, donde los voceros y líderes comunales desde su mismidad, tienen saberes y experiencias diferentes.

Se puede señalar que desde esta concepción social integrado con los sujetos, nace una gerencia emancipadora: que muestra una organización social que se gerencia a través de los voceros y líderes comunales, donde se adjudican roles en apego ético por quienes se asumen como representantes de las organizaciones populares, en un entorno que teóricamente solo permite el protagonismo participativo, pero que en diversas ocasiones se enfrenta a la representatividad que permite concebir un concepto de gerencia emancipadora. En una estructura social constituida de forma horizontal, que se acopla con la Responsabilidad Social, en una nueva concepción que la visualiza desde lo interno a lo externo, que prospera del pensar de quien ejerce el liderazgo; todo ello para empoderar a sus miembros y lograr la felicidad de los integrantes de la comunidad.

Es común al afrontar enfoques de gerencia indicar la competencia, rendimiento, productividad, entre otros, como aspectos interrelacionados y estrechamente involucrados en la misma; los cuales no se ajustan al enfoque alternativo de la gerencia que se propone en este estudio, por ser más importante valorar el compromiso, participación y la solidaridad. A este respecto Camacaro (2010), afirma que "El primer valor del bien común sobre el cual se asienta la Gerencia es la libertad, (...)". Donde la "libertad individual está socialmente vinculado, lo cual introduce el segundo principio en el que se asienta la calidad de vida humana: la equidad" (pp. sin número). Esta investigación hace mención a los principios de equidad, libertad y democracia, donde mientras más libertad más posibilidades de elección y más confusión, las Comunas deben ser centros de participación colectiva, con base al pensamiento estratégico de acercar la misión a la visión comunal.

Según lo sostenido por Álvarez (2004) y Cunill (1991), en otros países latinoamericanos, donde resalta la llamada participación ciudadana de Ecuador, se produce una participación con interconexión entre la sociedad y el Estado, encaminada a trasladar la participación del estado al ciudadano. En el caso venezolano, la participación forma parte de los preceptos constitucionales. Partiendo de la investigación que se presenta, se infiere que la calidad de vida de la sociedad en general y de las organizaciones comunitarias depende de las acciones de los 
voceros y líderes, en un entorno donde según la Asamblea Nacional de la República Bolivariana de Venezuela (2010), Ley Orgánica de las Comunas en sus artículos 1 y 2, se "(...)desarrollan la participación protagónica mediante formas de autogobierno (...)", principios y valores donde resaltan la "participación democrática y protagónica, interés colectivo (...), corresponsabilidad (...), cogestión, autogestión, autogobierno, cooperación, solidaridad (...)", entre otros.

De las entrevistas aplicadas a los voceros, se concluye que las personas que se asumen como voceros, en ocasiones cumplen sus funciones comprometido con lineamientos políticos partidistas, otros en apego al sentido de justicia basado en lineamientos constitucionales y leyes. Los voceros y guías comunales que tendrán éxito a futuro son los que están explorando adelante del horizonte, donde se examinan cualidades singulares que se necesitan para crear una clase diferente de organización (Hesselbein et al., 2006). Aun cuando existen directrices a nivel nacional, en las Comunas no se actúa de forma idéntica, sus acciones dependen de quienes participan en el abordaje de los problemas locales desde el compromiso y la Responsabilidad Social.

Es imperativo revelar las habilidades de los voceros y líderes comunales, para tomar lo mejor de cada integrante de la Comuna para cambiar de manera positiva la situación actual, sin dejar de tomar en cuenta las opiniones de los demás frente a sus propias ideas, lo cual llevará a cuestionar sus suposiciones y decidirá qué cambios necesita para influir en las demás personas para convertirse en un líder eficaz.

Las nuevas ideas e invenciones en el campo comunal están relacionadas con nuevos conceptos, que impulsen a tomar decisiones asertivas, en base a los roles que cada vocero y líder comunal ejerce y lógicamente con arraigo ético, porque no puede existir gerencia y responsabilidad social en las Comunas sin principios. Solo conociendo el entorno social, se puede fomentar la emancipación en la estructura político social que la conforma.

Todo lo anterior se logra, si los líderes y voceros comparten las responsabilidades para avanzar en la consecución de los logros organizacionales, alejándose de lo que teóricamente se conoce como una organización con problemas de aprendizaje. Sin pretender ser sólo leales a un cargo 0 actuar individualmente, exclamando: "Yo soy mi puesto", que surge: "Cuando las personas de una organización se concentran únicamente en su puesto, no sienten mayor responsabilidad por los resultados que se generan cuando interactúan todas las partes" (Senge, 2010, p. 30).

Una gerencia emancipadora dentro de la complejidad y la acción comunicativa, evoca una nueva forma de percibir al líder, con sus saberes y experiencias, habilidades y destrezas para manejar grupos sociales, responsables con ellos mismos y ante su entorno, que deben ser conscientes y actuar con conciencia, a través de procesos en construcción referidos a la toma de decisiones y el empoderamiento que coadyuven a conquistar logros en el entorno comunal.

Todo ello implica novedosas formas de pensar orientadas al gerente en formación, con altos niveles éticos, con capacidad de satisfacer las nuevas estructuras y de considerar lo social, con una nueva visión de compromiso que va desde lo personal y permea lo comunal, de una responsabilidad a la inversa que nace del interior del líder social y modifica su entorno social, para luego volver a transformarse. Por el simple hecho de ser humanos, donde el líder actuando como vocero y la comunidad organizada representada como un colectivo, se convierten en sujetos estratégicos para crear valores compartidos que los lleve a una construcción libre en un entorno que se convierte en su desafío para la construcción de un mundo solidario y justo. 
Un gerente que se permite soñar, responsable con él mismo y hacia los demás, es quien asume sus tareas dentro de la complejidad de una forma transcendental y transformadora, donde su voz será la voz del otro solo con apego a la ética para consolidar una Gerencia Emancipadora, socialmente responsable. Todo esto se debe asumir desde el enfoque planteado por Covey (2006), quien explica que, "Los principios correctos son como brújulas: siempre señalan el camino" (p. 19). Además, este reconocido autor agrega que: "(...) Sí son, en cambio, principios fundacionales que consecuentemente aplicados se convierten en hábitos que permiten transformaciones fundamentales en los individuos, las relaciones y las organizaciones" (p. 19).

De manera particular, se considera que la interrelación entre la gerencia y responsabilidad social requiere de enfoques que proporcionen inteligibilidad para la construcción colectiva basada en una postura epistémica compleja del talento gerencial representado por cuanto posee: habilidades comunicativas con una nueva perspectiva axiológica asentada en la ética que impulse una racionalidad distinta en lo político, social y cultural.

Considerando lo anterior se evalúa el criterio de Pertúz (2018), quien sostiene que “(...) los miembros de una organización, además de requerírseles una serie de condiciones específicas (...) se les demandará (...) la ética. No bastaran las competencias técnicas e intelectuales, hará falta el comportamiento ético" (p. 328). Un discurso donde afloren las competencias para gestionar en los escenarios comunales. Así la capacidad práctica, facilite la interacción humana toda vez que intervienen para enrumbar elocuentemente el empoderamiento a través de la toma de decisiones de equipos sociales responsables de ellos y de su entorno, basados en la ética, los valores y el cumplimiento de normas y leyes establecidas. Pretendemos con todo lo anterior, repensar a la nueva gerencia en función a la interacción (actividad comunicativa) de los sujetos participantes (actores sociales: Voceros y líderes comunales) como elemento fundamental para el logro del bienestar social (Ver Diagrama Teórico).

Diagrama N¹. Diagrama Teórico: Gerencia y responsabilidad social: construcción colectiva desde la complejidad y la acción comunicativa 


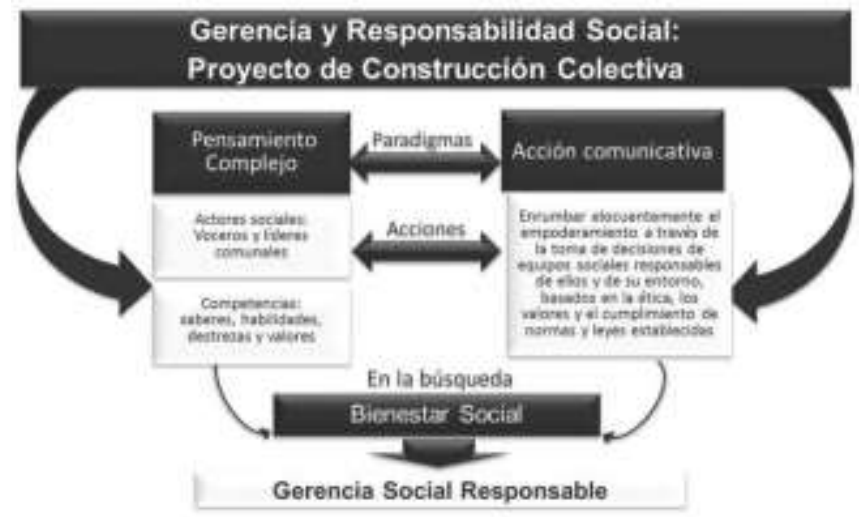

Fuente: elaboración propia.

\section{Reflexiones finales}

Parece cada vez más evidente que la sociedad venezolana se transforma de una manera particular y única, con un gran peso en la estructura social que toma decisiones en colectivo y afecta la forma como globalmente vemos la responsabilidad, por ser quienes conforman las comunidades; los que según la Carta Magna deben asumir los retos asociados a construcción de obras civiles, cuidar la sobreexplotación de los recursos naturales o la contaminación ambiental, entre tantos otros compromisos.

En otras palabras, aparece una posibilidad de repensar la Responsabilidad Social, ahora bien desde los actores comunales, de lo interno a lo externo; quienes son los protagonistas de la construcción de una nueva perspectiva de la Gerencia, que aflora producto de las modificaciones legales, asociada a la política y la manera de concebir el proceso democrático emergente, implica que los gestores públicos que ejercen la gerencia a partir de nuevos espacios de participación y en apego a valores éticos, articulen las redes sociales y políticas que impulsen la transformación desde lo interno, formas de pensarse, concebirse y de cómo su responsabilidad personal afecta el logro de las metas colectivas.

Se recoge de los juicios emitidos por los actores sociales de una resistencia para asociar el término Gerencia y Responsabilidad Social, así como también, el hecho de vincular estos constructos en el ámbito comunal. Tal vez las opiniones de los voceros estén influenciadas por el desconocimiento y por el compromiso de su aplicación en la esfera socio comunal.

No obstante supera un cambio de la semántica sobre la temática estudiada o maquillar los conceptos que existen, en efecto es un abordaje que asciende a las organizaciones inteligentes, o de gerencia social; es repensar la gerencia en base a nuevos criterios de análisis y síntesis. La nueva gerencia toma en consideración la gestión del cambio a través del liderazgo transformacional, trabajo en equipo, empoderamiento, motivación, la comunicación por medio de innovadoras redes de información, entre otros medios estratégicos. En consecuencia, estructuralmente deben ser organizaciones flexibles y horizontales, por permitir la ejecución de proyectos y las metas que se propongan en el entorno comunal. Convirtiendo el entorno 
Gerencia y responsabilidad social: construcción colectiva desde la complejidad y la acción comunicativa

comunal en el lugar en el cual los voceros aplican sus saberes e identifican otras estructuras de sus prácticas de vida, también se prueba su sensibilidad, su carácter y su voluntad para construir nuevos conocimientos, apegados a una toma de conciencia ética, con que lograr decisiones por consenso.

Se requiere de un liderazgo transformacional compartido, donde los voceros alcanzaran los objetivos mediante la cooperación y esfuerzo de todos. Un nuevo modelo no deja de lado la competencia interna entre sus miembros, porque sería ir en contra de la forma natural del hombre, de su ego y asumir protagonismo, aceptando formas diferentes de pensar de los ciudadanos que se expresan en las asambleas de ciudadanos.

Lo idea es contar con una estructura comunal capaz de cumplir el fin para el cual se constituyó, especialmente que impulse los programas y proyectos nacionales para el beneficio colectivo. Las comunas están instituidas por voceros y los mismos deben tener ciertas características que les concedan un papel de relevancia en el entorno comunal; y tienen como objeto ser líderes naturales, representativos de la comunidad, fidedignos, creativos, consensuados, elocuentes, inspiradores, solidarios, colaboradores, optimista, generosos, hábiles para enseñar y aprender, administradores de los recursos financieros, comunicadores entre la sociedad y las instancias superiores, visionarios a la hora de toma decisiones bajo incertidumbre, manejar conflictos y asumir retos del mundo cambiante y complejo. En el sistema comunal, no se puede señalar que necesariamente quien tenga mayor nivel de instrucción será el mejor vocero, pero lleva una gran carga asociada a la formación integral.

Todo lo anterior, nos conducirá a la construcción de una gerencia emancipadora dentro de la complejidad, que evoca una nueva forma de concebir lo social de donde nace, se define como una pieza engranada que entrama saberes, usanzas, conocimientos y valores de los líderes para manejar grupos sociales, responsables ante su entorno, conscientes y responsables de actuar con conciencia, que a través de procesos en desarrollo referidos a la toma de decisiones, el empoderamiento, ayudan en el proceso de conducir a la comunidad al logro de los objetivos plasmados en el marco legal vigente.

Una vez presentados los avances investigativos alcanzados hasta ahora, se invita a quien quiera seguir repensando la gerencia y responsabilidad social en las comunas, rompiendo paradigmas.

\section{Referencias bibliográficas}

Álvarez, Lucia. (2004). La sociedad civil en la Ciudad de México. Actores sociales, oportunidades y esfera pública. Centro de Investigaciones Interdisciplinarias de Ciencias y Humanidades-Universidad Nacional Autónoma de México, México.

Asamblea Nacional de la República Bolivariana de Venezuela - ANRBV (2000). Constitución de la República Bolivariana de Venezuela. Gaceta Oficial $N^{\circ} 5453$, del 24 de marzo de 2000. Venezuela.

Asamblea Nacional de la República Bolivariana de Venezuela - ANRBV (2010). Ley Orgánica de las Comunas (Gaceta Oficial No 6.011 Extraordinario del 21 de diciembre de 2010. Venezuela.

Barreto, Juan. (2011). La Comuna. Fundación Polar (primera Edición). Venezuela.

Bauman, Zymunt. (2000). Modernidad líquida. Fondo de cultura económica, S.A. (tercera reimpresión). Argentina. 
Blanco, Maryoly. (2018). Gerencia Participativa en el contexto humanista. Revista Ciencias Sociales y Educativas. Vol. VIII, Nro. 2. Número especial "Sociedad y Gerencia". Venezuela. (Pp. 111-121). Extraído de: https://issuu.com/revistacienciassocialesyeducativas/docs/volviiinro2esg

Camacaro, Pedro. (2010). Hacia la epistemología de la gerencia. Contribuciones a la Economía.Issue 2010-03, Venezuela. (Pp. Sin número). Extraído de: http://www.eumed.net/ce/2010a/prc.htm

Carrasco, José Bernardo y Calderero, José Fernando. (2000). Aprendo a Investigar en educación. Ediciones Rialp. España.

Covey, Stephen. (2000). Los siete hábitos de las personas altamente efectivas. Paidós. España.

Cunill, Nuria. (1991). La participación Ciudadana. Centro Latinoamericano de Administración para el Desarrollo. Venezuela.

Gadamer, Hans-Georg. (1993). Título original: Wahrheitund Methode. Tradujeron: Ana Agud Aparicio y Rafael de Agapito. J.C.H., Mohr (Paul Siebeck) Tübingen. Traducido: Verdad y método. Fundamentos de una hermenéutica filosófica. Ediciones Sígueme, S.A. (quinta edición). España.

Habermas, Jürgen. (1987). Theorie deskommunidativenHandelns. (Vers. castellana de M. Jiménez Redondo: Teoría de la acción comunicativa, Grupo Santillana de Ediciones, S. A. (2 vols.). España.

Heidegger, Martin. (2003). Ser y tiempo. Editorial Fondo de Cultura Económica. Editorial Trotta, España.

Hesselbein, Frances; Goldsmith, Marshall y Beckhard, Richard. (2006). El líder del Futuro. Editorial Deusto. España.

Husserl, Edmund. (1962). Ideas relativas a una fenomenología pura y una filosofía fenomenológica. Fondo de Cultura Económica. España.

Jansen, Harrie. (2013). La lógica de la investigación por encuesta cualitativa y su posición en el campo de los métodos de investigación social. Paradigmas: Una Revista Disciplinar de Investigación. Vol. 5, No. 1. España. (Pp. 39-72). Extraído de: https://dialnet.unirioja.es/descarga/articulo/4531575.pdf

Marcano, Josseilin. (2017). Análisis crítico de la gerencia y transformación en la educación universitaria, desde diversos postulados. Instituto Internacional de Investigación y Desarrollo Tecnológico Educativo INDTEC, C.A. Venezuela, Edición Especial Febrero-Abril 2017. (Pp. 275-294). https://doi.org/10.29394/scientific.issn.25422987.2017.0.0.15.275-294

Marshall, Martin. (2016). Sampling for qualitative research. Family Practice. Oxford University Press. Volumen 13, Número 6. Gran Bretaña. (Pp. 522-526). Extraído de:

https://www.alnap.org/system/files/content/resource/files/main/family-practice-1996marshall-522-6.pdf

Maxwell, Joseph. (1996). Qualitative research design: an interactive approach. Traducción de María Luisa Graffigna. Un modelo para el diseño de investigación cualitativo. Sage Publications. EEUU. 
Mayol, Diogénes. (2007). La confianza en la investigación ¿valor o valiosa? Logoi. Revista de filosofía. $N^{\circ} 12$, Semestre julio-diciembre 2007.Venezuela. (Pp. 37-51). Extraído de: http://biblioteca2.ucab.edu.ve/anexos/biblioteca/marc/texto/AAC2855_14.pdf

Mendieta, Giovane. (2015). Informantes y muestreo en investigación cualitativa. Investigaciones Andina. Vol. 17, núm. 30, abril-septiembre, 2015. Colombia. (Pp. 1148-1150). Extraído de: https://www.redalyc.org/pdf/2390/239035878001.pdf

Mendoza, Johana. (2018). La epistemología crítica: Un Enfoque para la Construcción del Pensamiento Gerencial Emergente. Sapienza Organizacional. Vol. 5, núm. 10. Venezuela. (Pp. 143-165). Extraído de: https://www.redalyc.org/jatsRepo/5530/553057245008/html/index.html

Morín, Edgar. (2003). Educar en la era planetaria (primera Edición). Editorial Gedisa. España. Morín, Edgar. (2005). Introduction a la pensé complexe. Traducción de Marcelo Pakman. Introducción al pensamiento complejo. Editorial Gedisa (octava reimpresión). España.

Mühr, Thomas y Friese, Susanne. (2004). Manual de usuario para ATLAS.ti. Versión 7.5.4, (2nd Edición). Alemania: Desarrollo de software científico. Extraído de: https://doc.atlasti.com/ManualWin.v9/ATLAS.ti_ManualWin.v9.pdf

Pertúz, Fredy. (2018). Liderazgo Transformacional en Empresas Sociales Desde la perspectiva Ética de la Responsabilidad Social Empresarial. Telos, Revista de Estudios Interdisciplinarios en Ciencias Sociales. Vol. 20, núm. 2. Venezuela. (Pp. 377-400). https://doi.org/10.36390/telos202.08

Ramírez, Marbelis. (2012). Estilos de liderazgo y sus enfoques gerenciales. Una aproximación teórica-metodológica para el análisis de la dirección organizacional. Revista de Ciencias Sociales (Ve). Vol. XVIII, núm. 1, enero-marzo, 2012.Venezuela. (Pp. 8998). Extraído de: https://www.redalyc.org/pdf/280/28022785007.pdf

Romero, Juan. (2006). Aproximación a una sociología de la gerencia. Gerencia pública y compromiso social. Red de revistas científicas de América Latina y el Caribe, España y Portugal (Redalcy). Gestión y política pública, año /vol. XV, nro. 001. México. (Pp. 49-82). Extraído de: https://www.redalyc.org/pdf/133/13315102.pdf

Savater, Fernando. (2004). El valor de elegir. Editorial Ariel. España.

Senge, Peter. (2006). La quinta disciplina. Editorial Granica. España.

Zavarce, Carlos; Briceño, Magally; Chacin, Migdy. (2009) Descriptores del pensamiento gerencial emergente. Visión Gerencial. Núm. 1, enero-junio, 2009. Venezuela. (Pp. 187-201).

Extraído

de: http://erevistas.saber.ula.ve/index.php/visiongerencial/article/view/839/0 